\title{
Narrowed temperature adaptability in non-natal osmotic environments of two euryhaline wanderers, dace and black porgy: implications for seasonal habitat changes
}

\author{
Masahiro Nakamura $^{1} \cdot$ Reiji Masuda $^{2} \cdot$ Katsumi Tsukamoto $^{3} \cdot$ Tsuguo Otake $^{1}$
}

Received: 17 September 2015 / Accepted: 3 December 2015 / Published online: 2 January 2016

(C) The Author(s) 2015. This article is published with open access at Springerlink.com

\begin{abstract}
Many euryhaline wanderer species exhibit seasonal habitat changes, and temperature is suggested to play a key role in this phenomenon. To examine this possibility, we tested the hypothesis that adaptable temperature ranges of euryhaline wanderers are narrower in a non-natal osmotic environment than in their natal osmotic environment using dace Tribolodon hakonensis, a freshwater born euryhaline fish, and black porgy Acanthopagrus schlegelii, a marine born euryhaline fish. In both species, all individuals survived for $48 \mathrm{~h}$ in all the tested temperatures in their natal osmotic environments. In non-natal osmotic environments, however, both low (dace: $6{ }^{\circ} \mathrm{C}$, black porgy: $10^{\circ} \mathrm{C}$ ) and high temperatures (dace: $30{ }^{\circ} \mathrm{C}$, black porgy: $33{ }^{\circ} \mathrm{C}$ ) significantly reduced their survival. These results indicate that euryhaline wanderers have a narrowed adaptable temperature range in non-natal osmotic environments. The similar trend observed in these two species of freshwater and marine fishes suggests that this may be a general
\end{abstract}

Masahiro Nakamura

nakamura@aori.u-tokyo.ac.jp

Reiji Masuda

reiji@ kais.kyoto-u.ac.jp

Katsumi Tsukamoto

tsukamoto.katsumi@nihon-u.ac.jp

Tsuguo Otake

otake@ aqua.fs.a.u-tokyo.ac.jp

1 Graduate School of Agricultural and Life Sciences, The University of Tokyo, Yayoi, Tokyo 113-8657, Japan

2 Maizuru Fisheries Research Station, Field Science Education and Research Center, Kyoto University, Nagahama, Maizuru, Kyoto 625-0086, Japan

3 College of Bioresource Sciences, Nihon University, Kameino, Kanagawa 252-0880, Japan characteristic in euryhaline wanderers and could be one of the causes of their seasonal movements.

Keywords Acanthopagrus schlegelli - Euryhaline wanderer · Japanese black porgy · Japanese dace $\cdot$ Natal and non-natal osmotic environment $\cdot$ Seasonal habitat change $\cdot$ Adaptable temperature $\cdot$ Tribolodon hakonensis

\section{Introduction}

Knowledge of the life history and ecology of fishes in estuaries has been accumulating in recent years [1], and it is becoming increasingly clear that many euryhaline wanderer species have common characteristics including seasonal habitat changes. The abundance and species richness of fishes residing in temperate estuaries is substantially reduced in winter [2-4]. For example, many marine born euryhaline species in the Hudson River and other species in the mid-Atlantic Bight estuaries along the US east coast migrate offshore or southward for overwintering [1, 3]. The Japanese black porgy Acanthopagrus schlegelii (family Sparidae), which moves into estuaries from the marine environment, is found in the brackish area of the Nakaumi Lagoon in Shimane Prefecture of Japan only in the summer season [5] and is suggested to move back to marine habitats during the other seasons. Conversely, freshwater born euryhaline wanderers such as the gizzard shad Dorosoma cepedianum and the Japanese dace Tribolodon hakonensis (family Cyprinidae) migrate back to freshwater habitats during the winter season for overwintering after they entered estuaries or coastal areas in summer [1, 6-9]. These observations suggest that euryhaline wanderers in the temperate zone migrate back to their natal osmotic environment (hypo-isotonic environment for freshwater species 
and hyper-isotonic environment for marine species) for wintering. Hereafter in this paper, both the hypertonic environment for freshwater species and the hypotonic environment for marine species are defined as a "non-natal osmotic environment".

Some ecological studies suggest that water temperature of the non-natal osmotic environment may play a key role in shaping the pattern of seasonal movement in euryhaline wanderers. Able and Fahay [1] indicated that the migration out of estuaries might be influenced by temperature, based on the fact that later egress periods or year-round residency can be observed within the same species, such as Anchoa mitchilli [10], in more southern estuaries where autumn cooling occurs later. Temperature-influenced habitat changes are also suggested from the geographical differences of migration patterns of Japanese dace. Overwintering migration of dace from coastal or estuarine areas into freshwater is known for the populations of rivers in northern Japan, including the Mukawa River in Hokkaido [7] and three rivers in Niigata Prefecture [9]. However, the population inhabiting the Kamogawa River in Mie Prefecture, in the middle part of Japan, moves back into freshwater only for reproduction in spring, without performing the overwintering migration [11]. Those differences may be caused by the coastal ocean temperatures in the winter season, because the monthly mean sea surface temperature of the coastal area in Hokkaido drops to $1-2{ }^{\circ} \mathrm{C}$ and to $10{ }^{\circ} \mathrm{C}$ in Niigata Prefecture in winter, while around the coast of Mie Prefecture it rarely drops to less than $15-16{ }^{\circ} \mathrm{C}$ (Japan Meteorological Agency: http://www.data.jma.go.jp/kaiyou/data/db/kaikyo/monthly/sst_HQ.html, accessed 6 May 2015). It is possible that in temperature conditions lower than $10{ }^{\circ} \mathrm{C}$, Japanese dace might not be able to adapt to seawater, which is a non-natal osmotic environment for them, and thus the northern populations migrate back to freshwater, a natal osmotic environment, in winter. Furthermore, there is an experimental study that has demonstrated that the low temperature tolerance of a euryhaline fish belonging to the family Sciaenidae decreases in the nonnatal osmotic environment [12]. The temperature range that individuals of euryhaline wanderer species can adapt to in non-natal osmotic environments may be narrower than that within their natal osmotic environment, and this might be one of the causes of seasonal habitat changes in euryhaline wanderers. However, experimental research has been conducted only for one species, the Atlantic croaker Micropogonias undulatus, and only for low temperature conditions [12]. Thus, how general this characteristic is among euryhaline wanderers, and whether this is consistent for high temperature conditions remain unclear.

The objective of this study, therefore, was to empirically determine if the adaptable temperature range of euryhaline wanderer fishes is narrower in a non-natal osmotic environment than that in their natal osmotic environment, and examine the possible reason of their seasonal habitat changes. Two euryhaline wanderer species, namely Japanese dace and Japanese black porgy belonging to families which have not yet been tested, were used for the experiment. Two groups of each species, one acclimated to the natal osmotic environment and the other to the non-natal osmotic environment, were tested for their survival rate when exposed to either high or low temperature. We also examined the relationships between body size and thermal stress tolerance in each osmotic environment.

\section{Materials and methods}

\section{Fish used for experiments}

The Japanese dace used in this study were collected in October of 2013 with a throw net in the pure freshwater area of the lower Enokigawa River near the estuary adjacent to Maizuru Bay. After being captured, individuals were kept in a 20-1 plastic bucket with a lid, which was filled with river water taken from the sampling site, and were transported to the Maizuru Fisheries Research Station (MFRS) of Kyoto University located in Maizuru, Kyoto Prefecture $\left(35^{\circ} 29 \mathrm{~N}, 135^{\circ} 22 \mathrm{E}\right)$. It took approximately 15 min to transport them. The standard length (SL) of the dace used in the experiments ranged between 64.6 and $146.5 \mathrm{~mm}$. Japanese black porgy used in this study were hatchery-born and reared in filtered seawater at MFRS under a natural photoperiod and water temperature. The SL of individuals ranged between 47.9 and $57.5 \mathrm{~mm}$.

About 200 dace and 80 black porgy were kept in 500-1 clear polycarbonate tanks (two tanks for dace and one for black porgy) filled with freshwater and seawater, respectively. The seawater tanks for black porgy were supplied with filtered seawater at a rate of $4 \mathrm{1} / \mathrm{min}$ and with enough aeration $(600 \mathrm{ml} / \mathrm{min})$. Tap water dechlorinated with sodium thiosulfate $(0.6 \mathrm{mg} / \mathrm{l})$ was used for rearing the dace in freshwater. Those three tanks were placed outdoors, covered with a roof, and exposed to the natural photoperiod. Fish were fed to satiation with commercial pellets (dace: Kawasakana-no-esa, GEX Co., Ltd., Japan; black porgy: Otohime S2, Marubeni Nisshin Feed Co., Ltd., Japan) once a day for about 10 days until being separated into different acclimation tanks.

\section{Acclimation of fish and the procedure of challenge tests}

Dace and black porgy were acclimated to both natal and non-natal osmotic water for more than 2 weeks prior to the experiment (dace: 80 individuals each; black porgy: 30 individuals each). Salinities of freshwater and seawater 
used for acclimation were $0.1-0.2 \mathrm{ppt}$ and $32-34 \mathrm{ppt}$, respectively. Two 500-1 clear polycarbonate tanks for each species, one for each osmotic condition, were used for the acclimation, and temperature was kept around $20{ }^{\circ} \mathrm{C}$ using a heater equipped with a thermostat. Since direct transfer to a non-natal osmotic environment can be lethal, fish were acclimated through several steps as follows. For acclimating the dace to seawater, they were first transferred to 15 ppt seawater from freshwater. Three days after this first transference, they were transferred to full strength seawater (32-34 ppt). Since black porgy seemed to be less tolerant to a non-natal osmotic environment than dace in a preliminary experiment, they were first transferred to $10 \mathrm{ppt}$ seawater from full strength seawater. After 1 day of acclimation, the salinity of the tank water was reduced to $5 \mathrm{ppt}$, followed by a 2 ppt degradation each day until the salinity reached 1 ppt. Fish were acclimated at $1 \mathrm{ppt}$ for $72 \mathrm{~h}$ and then transferred to freshwater (0.1-0.2 ppt). The two seawater tanks (one for each species) were supplied with filtered seawater at a rate of $41 / \mathrm{min}$ and well aerated $(600 \mathrm{ml} / \mathrm{min})$. Fishes in the two freshwater tanks (one for each species) were kept in water filtrated with three air-driven corner filters. About $1 / 3$ of the water in the freshwater tanks were exchanged every 4 days.

Challenge tests were conducted in the laboratory from 7 November to 3 December 2013 using two fish groups acclimated to natal and non-natal osmotic waters. Only fish with no injury and no sign of abnormal behavior were used in the experiments. Two water baths (width: $1800 \mathrm{~mm}$, length: $900 \mathrm{~mm}$, depth: $400 \mathrm{~mm}$ ) equipped with four chillers and two heaters were used to regulate the water temperature of the experimental tanks. Water in each water bath was circulated with two water pumps to make the temperature homogeneous throughout the bath. Six acrylic fiber experimental tanks (width: $450 \mathrm{~mm}$, length: $300 \mathrm{~mm}$, depth: $300 \mathrm{~mm}$ ) were set in each water bath. Three of them were filled with freshwater and the other three filled with full strength seawater. Thus, triplicates for the natal osmotic environment and non-natal osmotic environment treatments were prepared for each experimental water temperature. Temperatures to which the fish would be transferred were $6,10,15$, 20 (no change), and $30^{\circ} \mathrm{C}$ for dace and 10,20 (no change), and $33{ }^{\circ} \mathrm{C}$ for black porgy; thus, experiments with the two osmotic environments with three replications of each treatment for one species were conducted at five (dace) or three (black porgy) temperature treatments. Black porgy was examined at fewer temperature treatments compared to dace because of the limited number of fish available for use in the experiment. Each tank was aerated and held under light conditions of 12L-12D. Two experiments were conducted simultaneously using the two water baths.

Experimental tanks were set in the water baths for at least $24 \mathrm{~h}$ before the start of the experiment to adjust the water temperature of tanks to each test temperature. At the time of the experiment, 3-5 individuals in the acclimation tank were transferred to an acrylic fiber container (width: $280 \mathrm{~mm}$, depth: $170 \mathrm{~mm}$, height: $160 \mathrm{~mm}$ ) filled with acclimation water. The container was then put into the experimental tank with fish and acclimation water. Thus, the ambient water temperature of fishes did not change abruptly, and so we prevented death of fish by sudden thermal change. The number of fish in each tank was adjusted to between 3 and 5 individuals to make the biomass of each experimental tank approximately the same within each species. Therefore, the total numbers of individuals used in each experimental temperature change treatment were 13-15 for dace and 11-12 for black porgy.

It took $0 \mathrm{~min}\left(20^{\circ} \mathrm{C}\right.$ treatment) to $1-3 \mathrm{~h}$ for the temperature of the water in the containers to reach the targeted temperatures. Fish were released into the water of the experimental tanks after the water temperature of the container reached each experimental temperature. Water temperature of the container was checked constantly with a thermometer during this period and all transfers were started around 7:00 a.m. Containers were removed from the experimental tank as soon as fish were released and a lid was put on each experimental tank to prevent evaporation of water and the fish jumping out of the tank. Experiments were conducted for $48 \mathrm{~h}$ and tanks were checked for dead fish every $12 \mathrm{~h}$. When dead individuals were found, they were immediately removed from the tank and the standard length (SL) and body weight $(\mathrm{BW})$ were measured. Fish were defined as dead when no movement could be seen in any part of their body. The survival rate of each tank was calculated for 24 and $48 \mathrm{~h}$ after fish were exposed to the test temperature. The SL of dace in each experimental tank at the end of the experiment were not the same (Welch's $t$-test, $P<0.01$ ), presumably because of the low survival rate of small individuals during seawater acclimation. SL composition of black porgy was the same among the experimental tanks (Welch's $t$-test, $P>0.05$ ).

\section{Data analysis}

Prior to the statistical comparison of survival rate among treatments, variation in the triplicated data was tested. Because there was no significant difference in survival rates within each triplicated data (Fisher's exact test, $P>0.05$ ), data from each triplicated trial were pooled. Effects of SL and BW on the survival rate in the non-natal osmotic environments were examined by comparing the SL and BW between surviving and dead individuals. Three individuals or more from both surviving and dead groups were needed for this analysis, so only data of time points that fulfilled this requirement were used for the analysis. In the case of dace, data of the 24-h time point of $6{ }^{\circ} \mathrm{C}$ (5 individuals 
Table 1 Standard length (SL), body weight (BW) and the total number of individual fish used in each experimental temperature treatment for Japanese dace Tribolodon hakonensis and Japanese black porgy Acanthopagrus schlegelli

\begin{tabular}{|c|c|c|c|c|c|c|c|}
\hline \multirow[t]{2}{*}{ Species } & \multirow[t]{2}{*}{ Temperature $\left({ }^{\circ} \mathrm{C}\right)$} & \multicolumn{3}{|l|}{ Sea water } & \multicolumn{3}{|l|}{ Fresh water } \\
\hline & & SL & BW & $n$ & SL & $\mathrm{BW}$ & $n$ \\
\hline \multirow[t]{5}{*}{ Tribolodon hakonensis } & 6 & $116.3 \pm 12.4$ & $18.9 \pm 6.0$ & 15 & $104.4 \pm 19.5$ & $16.8 \pm 8.3$ & 14 \\
\hline & 10 & $119.1 \pm 8.4^{*}$ & $20.5 \pm 4.4^{*}$ & 15 & $101.6 \pm 15.2$ & $14.8 \pm 5.4$ & 13 \\
\hline & 15 & $123.3 \pm 9.2 *$ & $23.1 \pm 4.7^{*}$ & 14 & $100.1 \pm 19.3$ & $15.2 \pm 9.5$ & 15 \\
\hline & 20 & $119.9 \pm 9.0 *$ & $20.4 \pm 6.2^{*}$ & 14 & $88.32 \pm 26.1$ & $12.23 \pm 7.3$ & 15 \\
\hline & 30 & $102.0 \pm 17.2^{*}$ & $17.2 \pm 6.5^{*}$ & 14 & $80.3 \pm 30.5$ & $11.2 \pm 7.4$ & 14 \\
\hline \multirow[t]{3}{*}{ Acanthopagrus schlegelli } & 10 & $65.1 \pm 13.9$ & $7.2 \pm 4.4$ & 12 & $65.7 \pm 10.2$ & $10.1 \pm 4.2$ & 12 \\
\hline & 20 & $66.5 \pm 15.0$ & $8.6 \pm 5.6$ & 12 & $67.2 \pm 13.4$ & $9.6 \pm 5.8$ & 11 \\
\hline & 33 & $68.0 \pm 16.1$ & $9.3 \pm 5.8$ & 11 & $63.2 \pm 8.0$ & $8.4 \pm 2.7$ & 12 \\
\hline
\end{tabular}

* Seawater acclimated individuals were significantly larger compared to those acclimated to freshwater (Welch's $t$-test, $P<0.01$ ). SL and BW is expressed with mean \pm standard error

survived and 10 individuals were dead) and $30{ }^{\circ} \mathrm{C}$ ( 3 individuals survived and 9 individuals were dead) were used for the analysis. However, in the case of $10^{\circ} \mathrm{C}$, not enough dead individuals were obtained before the time of $24 \mathrm{~h}$, so the data of $48 \mathrm{~h}$ (11 individuals survived and 3 individuals were dead) was used for the analysis. For black porgy, data of $24 \mathrm{~h}$ at $10{ }^{\circ} \mathrm{C}(6$ individuals survived and 6 individuals were dead) and $33{ }^{\circ} \mathrm{C}$ (4 individuals survived and 8 individuals were dead) were used for analysis.

Survival rates were compared between natal and nonnatal osmotic environment acclimated groups at the same test temperature at each time point using Fisher's exact test. SL and BW were compared between surviving and dead individuals in the non-natal osmotic environment using Welch's $t$-test. The significance level of all the statistical tests was set at $\alpha=0.01$. Welch's $t$-tests were performed using Ekuseru-Toukei 2010 (Social Survey Research Information Co., Ltd., Japan) and Fisher's exact tests were performed using the statistical program $\mathrm{R}$ ( $\mathrm{R}$ Development Core Team, 2014; http://www.R-project.org).

\section{Results}

No significant differences in SL and BW of black porgy were observed between the fish used in the natal and nonnatal osmotic environment treatments (Table 1, Welch's $t$-test, $P>0.05)$. However, dace in the seawater treatment were significantly larger in SL and BW, with the exception of the $6{ }^{\circ} \mathrm{C}$ temperature treatment (Table 1 , Welch's $t$-test, $P<0.01$ ). This was due to the mortality of small individuals in full-strength seawater during the acclimation period before the experimental trials.

In dace, all individuals tested in freshwater survived at all experimental temperatures during the $48 \mathrm{~h}$ of the test period after being transferred to the new temperature

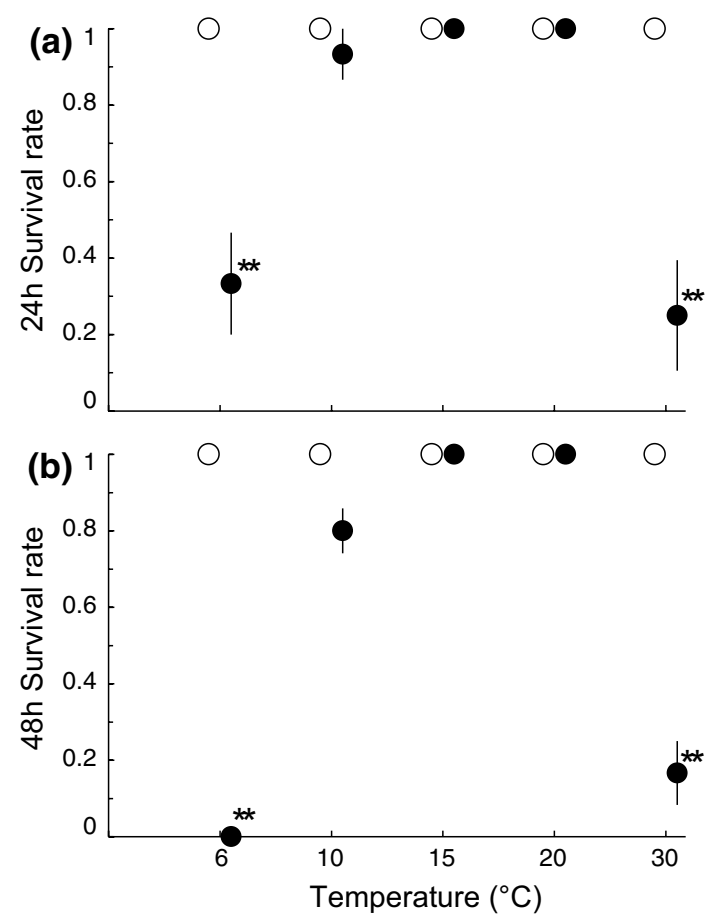

Fig. 1 Survival rate of Japanese dace Tribolodon hakonensis acclimated to natal (freshwater, open circle) and non-natal (seawater, closed circle) osmotic environments at a $24 \mathrm{~h}$ and b $48 \mathrm{~h}$ after the transference to test water temperatures. Vertical lines indicate standard error (SE). Asterisks indicate $P<0.01$ level of significant differences between the natal and non-natal osmotic environment acclimated treatments at each temperature

(Fig. 1b). Also, all individuals tested in seawater survived at temperatures of $20{ }^{\circ} \mathrm{C}$ and $15{ }^{\circ} \mathrm{C}$ for $48 \mathrm{~h}$. However, about $20 \%$ of the fish died at $10^{\circ} \mathrm{C}$, although there was no significant difference in survival rate between the natal and non-natal osmotic environments (Fisher's exact test, $P>0.05)$. Most fish died at $6{ }^{\circ} \mathrm{C}$ and $30{ }^{\circ} \mathrm{C}$ after $24 \mathrm{~h}$ in 

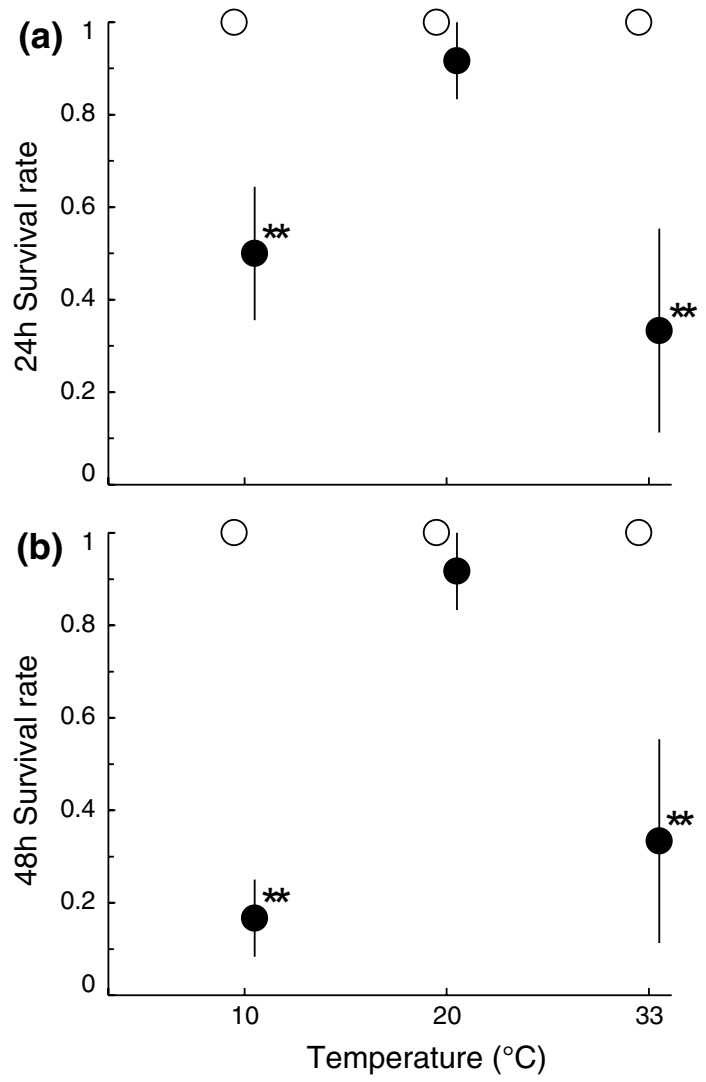

Fig. 2 Survival rate of Japanese black porgy Acanthopagrus schlegelli acclimated to natal (seawater, open circle) and non-natal (freshwater, closed circle) osmotic environments at a $24 \mathrm{~h}$ and b $48 \mathrm{~h}$ after the transference to test water temperatures. Vertical lines indicate standard error (SE). Asterisks indicate $P<0.01$ level of significant differences between the natal and non-natal osmotic environment acclimated treatments at each temperature

seawater, showing significantly lower survival rates compared to the freshwater acclimated groups at the same test temperatures (Fisher's exact test, $P<0.01$ ). The survival rate in seawater markedly decreased after $48 \mathrm{~h}$ at $6{ }^{\circ} \mathrm{C}$ and $30{ }^{\circ} \mathrm{C}$ (Fisher's exact test, $P<0.01$ ), with no fish surviving at $6{ }^{\circ} \mathrm{C}$ (Fig. 1a, b).

In black porgy, all individuals tested in seawater survived all experimental temperature changes. However, at 10 and $33{ }^{\circ} \mathrm{C}$, more than half of the fish acclimated to freshwater died after $24 \mathrm{~h}$ and showed a significantly lower survival rate compared to seawater acclimated groups at the same temperatures (Fisher's exact test, $P<0.01$ ). The decrease in survival rate of freshwater acclimated groups at 10 and $33{ }^{\circ} \mathrm{C}$ became more notable at $48 \mathrm{~h}$ (Fisher's exact test, $P<0.01$ ) (Fig. 2a, b).

In dace, there was no significant difference in SL and BW between surviving and dead fish in the non-natal osmotic environment in any of the treatments (Fig. 3a, b). In black porgy, surviving individuals were significantly larger and heavier than dead ones at $10{ }^{\circ} \mathrm{C}$ (Welch's $t$-test,
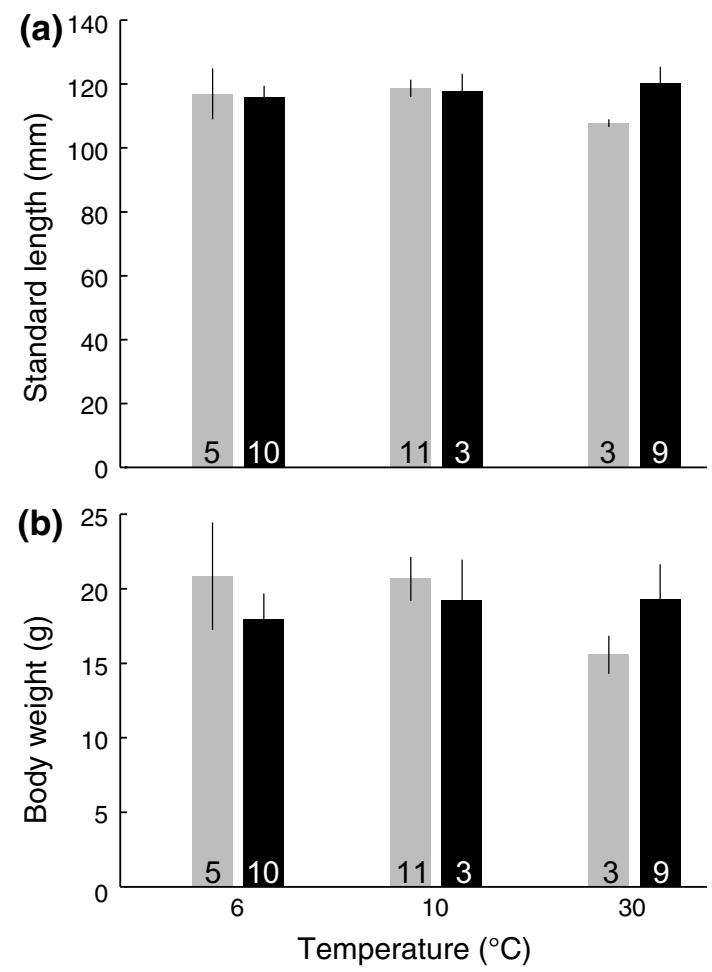

Fig. 3 Standard length (a) and body weight (b) of surviving (grey) and dead (black) individuals in non-natal osmotic environments of Japanese dace Tribolodon hakonensis. Lines on the bars show SE and numbers in columns indicate the total number of individuals used for analysis

$P<0.01$ ), and the same tendency was observed at $33{ }^{\circ} \mathrm{C}$, although the difference was not statistically significant (Welch's $t$-test, $P>0.05$ ) (Fig. 4a, b).

\section{Discussion}

This study revealed that the survival rates of fish acclimated to non-natal osmotic environments were markedly reduced at both high and low water temperatures, suggesting that the temperature ranges at which they can survive in the non-natal osmotic environments were narrower than those in the natal osmotic environments. The non-natal osmotic environment acclimated group of dace used for the challenge test was significantly larger than those used for the natal osmotic environment. The size difference was due to the mortality of small individuals during the 2-week preacclimation period in seawater, which suggests that small fish are less tolerant of living in seawater.

For the dace used in the challenge test, there was no difference in body size between those that survived and died in the non-natal osmotic environment. Also, there was no mortality in the freshwater treatment group. These results indicate that there is no clear relationship between temperature 

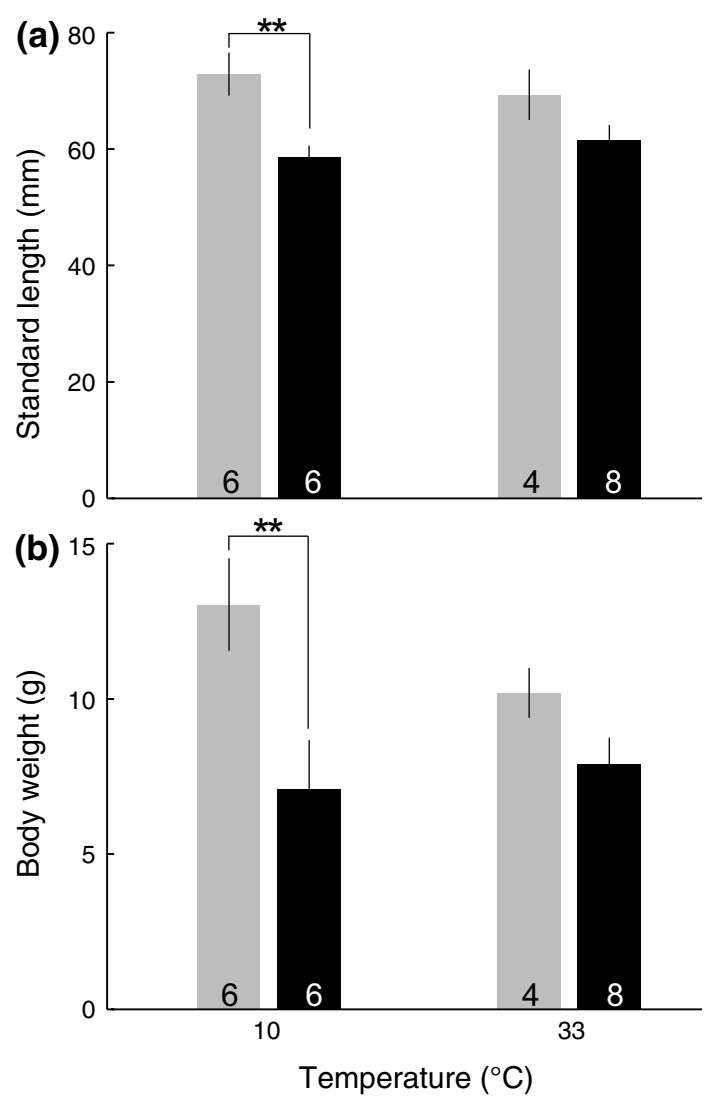

Fig. 4 Standard length (a) and body weight (b) of surviving (grey) and dead (black) individuals in non-natal osmotic environments of Japanese black porgy Acanthopagrus schlegelii. Lines on the bars show SE and numbers in columns indicate the total number of individuals used for analysis. Asterisks indicate $P<0.01$ level of significant differences between dead and surviving individuals at the same temperature

tolerance and body size in dace used in the experiment. Thus, although there was a significant size difference between those used in natal and non-natal osmotic environment treatments in dace, the high mortality observed in the seawater acclimated group can apparently be attributed to a narrowed adaptable temperature range in the non-natal osmotic environment, which was also the case for black porgy that had no size difference between treatments.

Low temperature tolerance in fishes during osmotic changes is generally governed by the ability to maintain ionic balances at both the cellular and organismal level [13-15]. Thus, individuals that died at low temperature may have failed in osmoregulation. Nevertheless, the direct cause of the high mortality observed both at high and low temperature conditions in non-natal osmotic environments remains unknown. Measuring the plasma osmolarity of individuals used for the experiment would help reveal this. Indeed, a recent study has reported that ion transport greatly decreases in cold temperatures for mummichog
Fundulus heteroclitus in seawater [16], so this may also be a factor for the species in our study.

The size-selective mortality of smaller individuals of black porgy under a non-natal osmotic environment during the temperature change trials may also be related to osmoregulatory factors. Allanson et al. [17] and Martin [18] reported a similar tendency in which smaller fish were more vulnerable to temperature-induced osmotic stress than larger ones. This may be because smaller individuals have larger gill surface area/body mass ratio compared to larger individuals. In contrast, we did not observe any size-selective mortality in dace used for the challenge tests. Hurst and Conover [19] also found that there was no effect of body size on the temperature and salinity tolerance of young-of-the-year striped bass. Allometry of gill surface area to body mass might influence the tolerance to osmotic stress only in certain species or body sizes. Further study would be required to reveal the physiological mechanisms underlying the relationships between tolerance to temperature-induced osmotic stress and body size.

To our knowledge, our study is the first to demonstrate that the adaptability of euryhaline wanderers to non-natal osmotic environments decreases not only in low temperature conditions but also in high temperature conditions. Although there is no evidence yet that dace or black porgy avoid the non-natal osmotic environment in extremely high temperature conditions, such cases are known for other species. Spotted hake Urophycis regia, a euryhaline wanderer marine species, is known to egress from the estuary in summer as water temperature increases [1,20,21], possibly indicating that this species avoids hypotonic conditions under high temperature conditions. Perhaps future studies may find evidence that dace and black porgy might avoid the non-natal osmotic environment in extremely high temperature conditions, especially considering the warming trend in coastal waters [22, 23].

Lankford and Targett [12] reported that Atlantic croaker, a marine species, has a reduced low temperature tolerance in low salinity water. The fact that dace, black porgy and Atlantic croaker, which belong to various taxa, show the same trend may suggest that narrowed temperature adaptability in non-natal osmotic environments is a general characteristic in euryhaline wanderers and could be one of the causes of their seasonal movements.

This is insightful from a phylogenetic perspective because recent studies suggest that the diadromous species of salmonids, anguillids and osmerids are derived from species living in a single osmotic environment via euryhaline wanderer species [24-26]. For example, ancestral euryhaline wanderer species may have succeeded in expanding their adaptable temperature range to non-natal osmotic environments and became able to stay there for the whole year at latitudes with seasonal temperature changes, which is a common migratory pattern among diadromous species with multiple-year life spans. In fact, some evidence 
of residual characteristics similar to those of Japanese dace, Japanese black porgy and Atlantic croaker may be that primitive salmonid species such as brook trout Salvelinus fontinalis are suggested to have inferior low temperature tolerance in seawater compared to the more recently diverged [27] Atlantic salmon Salmo salar and rainbow trout Oncorhynchus mykiss [28]. In addition, primitive salmonid species including brook trout are known to be in the sea only during the spring-summer season [29].

Therefore, comparative studies about the adaptable temperature range to non-natal osmotic environments between primitive and recently diverged salmonids as well as additional euryhaline wanderer species might shed light on the physiological processes influencing the evolution of diadromous fishes. Other types of future research should examine the tolerances of euryhaline wanderer fishes to temperature changes over longer time periods, since our study only examined the effect of rapid changes. Studies on changes in individual plasma osmolality should also be conducted to determine the relationships between survival and osmoregulatory ability while under temperature stress.

Acknowledgments We sincerely thank Dr. Kohji Takahashi (Nagasaki University) for technical support in collection and rearing of fishes. We are also grateful to Drs. Mari Kuroki (The University of Tokyo), Michael J. Miller (Nihon University), two anonymous reviewers, and Dr. Yutaka Kurita for constructive comments on the manuscript.

Open Access This article is distributed under the terms of the Creative Commons Attribution 4.0 International License (http://creativecommons.org/licenses/by/4.0/), which permits unrestricted use, distribution, and reproduction in any medium, provided you give appropriate credit to the original author(s) and the source, provide a link to the Creative Commons license, and indicate if changes were made.

\section{References}

1. Able KW, Fahay MP (2010) Ecology of estuarine fishes. The Johns Hopkins University Press, Maryland

2. Day JW, Hall CAS, Kemp WM, Yanez-Arancibia A (1989) Estuarine ecology. John Wiley \& Sons, New York

3. Able KW, Fahay MP (1998) The first year in the life of estuarine fishes in the Middle Atlantic Bight. Rutgers University Press, New Brunswick NJ

4. Ishitobi Y, Hiratsuka J, Kuwabara H, Yamamuro M (2000) Comparison of fish fauna in three areas of adjacent eutrophic estuarine lagoons with different salinities. J Mar Syst 26:171-181

5. Yokoo T, Mito T, Iwasaki T, Sasaki T, Michine T, Aranishi F (2010) Spatial and temporal variation of fish assemblages surveyed by set-nets in Nakaumi Lagoon. Jap J Limnol 71:11-18 (in Japanese with English abstract)

6. Hildebrand SF, Schroeder WC (1928) Fishes of Chesapeake Bay. Bull US Bur Fish 43:1-366

7. Sakai H (1995) Life-histories and genetic divergence in three species of Triborodon (Cypriniodae). Mem Fac Fish Hokkaido Univ 42:1-98
8. Murdy EO, Birdsong RS, Musick JA (1997) Fishes of Chesapeake Bay. Smithsonian Institute Press, Washington DC

9. Katano O, Nakamura T, Abe SI, Baba Y (2010) Population density, growth and migration via the sea to different streams of Japanese dace Tribolodon hakonensis in lower reaches of small streams. Ichthyol Res 57:1-9

10. Vouglitois JJ, Able KW, Kurtz RJ, Tighe KA (1987) Life history and population dynamics of the bay anchovy in New Jersey. T Am Fish Soc 116:141-153

11. Ishizaki D, Otake T, Sato T, Yodo T, Yoshioka M, Kashiwagi M (2009) Use of otolith microchemistry to estimate the migratory history of Japanese dace Tribolodon hakonensis in the Kamo River, Mie Prefecture. Nippon Suisan Gakkaishi 75:419-424 (in Japanese with English abstract)

12. Lankford TE, Targett TE (2001) Low-temperature tolerance of age-0 Atlantic croakers: recruitment implications for US midAtlantic estuaries. T Am Fish Soc 130:236-249

13. Maetz J, Evans DH (1972) Effects of temperature on branchial sodium exchange and extrusion mechanisms in the seawateradapted flounder Platichthys flesus L. J Exp Biol 56:565-585

14. Toneys ML, Coble DW (1980) Mortality, hematocrit, osmolality, electrolyte regulation, and fat depletion of young-of-the-year freshwater fishes under simulated winter conditions. Can J Fish Aquat Sci 37:225-232

15. Hochachka PW (1988) Channels and pumps-determinants of metabolic cold adaptation. Comp Biochem Physiol B 90:515-519

16. Buhariwalla HEC, Osmond EM, Barnes KR, Cozzi RRF, Robertson GN, Marshall WS (2012) Control of ion transport by mitochondrion-rich chloride cells of eurythermic teleost fish: cold shock vs. cold acclimation. Comp Biochem Physiol A 162:234-244

17. Allanson BR, Bok A, van Wyk NI (1971) The influence of exposure to low temperature on Tilapia mossambica Peters (Cichlidae). II. Changes in serum osmolarity, sodium and chloride ion concentrations. J Fish Biol 3:181-185

18. Martin TJ (1988) Interaction of salinity and temperature as a mechanism for spatial separation of three co-existing species of Ambassidae (Cuvier) (Teleostei) in estuaries on the south-east coast of Africa. J Fish Biol A 33:9-15

19. Hurst TP, Conover DO (2002) Effects of temperature and salinity on survival of young-of-the-year Hudson River striped bass (Morone saxatilis): implications for optimal overwintering habitats. Can J Fish Aquat Sci 59:787-795

20. Barans CA (1972) Spotted hake, Urophycis regius, of the York River and lower Chesapeake Bay. Chesapeake Sci 13:59-62

21. Burr BM, Schwartz FJ (1986) Occurrence, growth, and food habits of the spotted hake, Urophycis regia, in the Cape Fear Estuary and adjacent Atlantic Ocean, North Carolina. Northeast Gulf Sci 8:115-127

22. Freeland HJ (1990) Sea surface temperatures along the coast of British Columbia: regional evidence for a warming trend. Can J Fish Aquat Sci 47:346-350

23. Caputi N, De Lestang S, Feng M, Pearce A (2009) Seasonal variation in the long-term warming trend in water temperature off the Western Australian coast. Mar Freshwater Res 60:129-139

24. Ishiguro NB, Miya M, Nishida M (2003) Basal euteleostean relationships: a mitogenomic perspective on the phylogenetic reality of the "Protacanthopterygii". Mol Phylogenet Evol 27:476-488

25. Dodson JJ, Laroche J, Frederic L (2009) Contrasting evolutionary pathways of anadromy in euteleostean fishes. Am Fish Soc Symp 69:63-77

26. Inoue JG, Miya M, Miller MJ, Sado T, Hanel R, Hatooka K, Aoyama J, Minegishi Y, Nishida M, Tsukamoto K (2010) Deepocean origin of the freshwater eels. Biol Lett 6:363-366

27. Murata S, Takasaki N, Saitoh M, Okada N (1993) Determination of the phylogenetic relationships among Pacific salmonids 
by using short interspersed elements (SINEs) as temporal landmarks of evolution. Proc Natl Acad Sci USA 90:6995-6999

28. Saunders RL, Muise BC, Henderson EB (1975) Mortality of salmonids cultured at low temperature in sea water. Aquaculture $5: 243-252$
29. McCormick SD (1994) Ontogeny and evolution of salinity tolerance in anadromous salmonids: hormones and heterochrony. Estuaries 17:26-33 